\title{
A Critical Review of Sensors for the Continuous Monitoring of Smart and Sustainable Railway Infrastructures
}

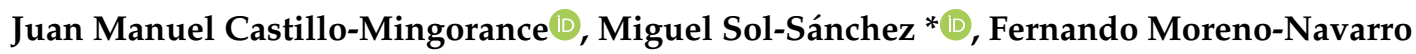 \\ and María Carmen Rubio-Gámez \\ Laboratory of Construction Engineering, University of Granada, C/Severo Ochoa s/n, 18071 Granada, Spain; \\ jumacami@ugr.es (J.M.C.-M.); fmoreno@ugr.es (F.M.-N.); mcrubio@ugr.es (M.C.R.-G.) \\ * Correspondence: msol@ugr.es
}

Received: 8 October 2020; Accepted: 9 November 2020; Published: 12 November 2020

\begin{abstract}
Real-time and continuous monitoring through smart sensors is considered to be the evolution of traditional track testing, enabling the earlier detection of the main failure modes that degrade railway tracks. Through carrying out preventive maintenance operations, infrastructure resources may be optimized, leading to smarter and more sustainable infrastructure. For this reason, under the larger goal of creating a synergy with various types of sensors for railway tracks, this article presents a critical review on the different, currently available sensors for smart and continuous monitoring. Specifically, the most appropriate monitoring technologies for each of the main railway track failure modes have been assessed and identified, thus deriving the advantages and capacities of each solution. Furthermore, this review presents some of the main experiences carried out to date in literature by using sensor technologies, such as strain gauges, piezoelectric sensors, fiber-optics, geophones and accelerometers. These technologies have proven to offer appropriate characteristics and accuracy for the continuous monitoring of a railway track's structural state, being capable of measuring different parameters, such as deflections, deformations, stresses or accelerations that would permit the technical tracking of various forms of degradation.
\end{abstract}

Keywords: real-time monitoring; rail track sensor; smart infrastructure; structural health monitoring; review

\section{Introduction}

The transport of both people and goods plays a fundamental role in the advancement of society and the economy. In recent years, mobility has greatly increased with an increased use of infrastructures, which in turn requires greater investments to conserve their functionality and safety [1]. This is accentuated by the fact that train circulation speed and capacity is increasing too, with the aim to reduce travel time and increase railway efficiency [2]. For this reason, to guarantee good track operability it is necessary to optimize the time, resources and costs for maintenance activities (which are increasing in frequency due to increased use).

In this sense, predictive maintenance is a management tool increasing in demand, due its high potential. For this purpose, continuous rail track monitoring plays a fundamental role for efficiently and reliably tracking the condition of the infrastructure. The use of smart and cutting-edge sensors and technologies to monitor the railroad would permit its continuous tracking, and enable the anticipation of future possible pathologies, turning current corrective maintenance into predictive maintenance, thus minimizing associated maintenance costs [3]. Through this, any premature degradation would also be avoided and, therewith, a decrease in the possible costs associated to the renewal of some components of the infrastructure, obtaining a more sustainable solution. 
The first monitoring systems date from 1872, when William Robinson invented the first track circuit used in a railway, which is still used nowadays. This system detects the presence of, or lack of, trains on the railway through the electric connections created between the wheels and rails [4]. Since then, sensor technology has evolved very quickly, further increasing in recent years. As a result, track deflection and change in railway stiffness, as well as other railway pathologies that could appear, in railroads can be monitored in different ways, from more simple systems (such as the traditional hydraulic jack-loading method, load cells or deflectometers) to the more sophisticated auscultator train [5]. However, this last solution, despite obtaining good results, is very expensive (one of them can cost more than EUR 45 million), and for this reason, its use is very limited. On the other hand, the use of traditional monitoring systems is limited to the punctual test in a specific area, and does not provide continuous monitoring. Therefore, the development and study of innovative technological solutions for real-time and continuous monitoring has great potential to improve the predictive maintenance possibilities of railways.

The high rate of development of sensor technologies in recent years has made sensors which are smaller, more accurate and cheaper. This increase in technical and economic viability has increased the interest of these devices in various fields such as environmental monitoring [6], bridge monitoring [7] or even testing lineal infrastructures [8]. Through their use, railway transportation could continue to be considered a reference for a modern, intelligent and efficient transportation, making it more competitive, and at the same time decreasing associated maintenance costs, via implementing continuous predictive maintenance.

Therefore, to achieve a smart monitoring system able to detect and predict the main modes of railway track failure, such as permanent deformations, change in the structural section, component fatigue failures and vibration or noise, it is necessary to determine the technology available in the market, its capacity and functionality, as well as, any case studies in which it has been used. Thus, this paper assesses the characteristics of the main types of smart sensors which have the potential to be used for the continuous monitoring of railway tracks, via studying their possible implementation in tracks per the main failure modes and providing understanding on the key parameters to measure in each mode.

For this purpose, the methodology followed consisted of, firstly, identifying and studying the main modes of railroad failure through the literature review of scientific indexed journals as well as technical reports. This revealed the principal factors that can accelerate track failure, and how they are commonly detected via conventional testing. Following on, the smart sensors with the highest potential for track monitoring were analyzed and compared using the current information available in scientific articles (collecting case studies from the last 5 years) as well as consulting technical guides from manufacturers. Finally, a discussion section provides an analysis of the information reviewed, assessing the suitability and potentiality of each sensor for the continuous monitoring of railway tracks per the main modes of railroad failures and the principal current demands.

\section{The Main Modes of Track Failure and Their Traditional Monitoring}

There are various different failure modes associated with railroads, which decrease the original quality of the tracks due to the degradation of the infrastructure. This depends on several factors such as railroad use, the environment or the possible failure of individual components that could occur during its service life. Despite there being other types of failure whereby the railroad could be rendered inoperable, this paper is focused on those to be carried out during the youth stage in ballasted tracks, given that this track typology is the most commonly used and where a higher level of monitorization is required. The most significant failures are explained in the following sections.

\subsection{Permanent Deformation and Rail Track Settlement}

Among the most typical failures in lineal infrastructures is related to the permanent deformations, which are more problematic than those with differential magnitudes due to changes in the resistant 
capacity of the bearing courses. With the continuous loading from thousands of trains, all these deformations are accumulated, giving way to differential rail track settlement. This problem is accentuated in the transition between two track areas with different stiffnesses, such as the transition from an embankment to a bridge or tunnel, or from transitioning between diverse geological areas. Transition zones could be considered as the most problematic areas for rail track settlement, where the rearrangements of the ballast would result in "hanging" sleepers, increasing the impact generated by the passing trains and thus, accentuating this problem increasingly over time. This failure mode could be considered as a vicious circle, where an increase in "hanging" sleeper problems generates a higher dynamic impact in the infrastructure from passing trains, and therewith, an increase in the rail track settlements.

Thus, this problem has traditionally been assessed by measuring the evolution of the track settlement in different sections along transition zones, as well as the height oscillations of the sleepers (referring back to the effect of "hanging" sleepers). Additionally, considering registering the acceleration, it is also possible to obtain the track deflections. For this purpose, the use of instrumentation such as Linear Variable Differential Transformers (LVDTs), high definition cameras and deflectometers is common [9-12]. For example, Mishra et al. [13] used a series of LVDTs to monitor a problematic section in a transition zone south of Philadelphia, USA. For this purpose, five LVDTs were used to collect the different settlements that were generated in each of the layers (Figure 1). Another example is Bowness et al. [14] who used remote video monitoring to assess track displacements. A webcam (with a higher resolution than conventional cameras) was attached to a telescope, which located all of the train structure layers, far away enough to avoid any possible impacts due to the deflection and vibration of the rail track. Particle image velocimetry was used to analyze the images taken during train circulation, with a resolution of $0.04 \mathrm{~mm}$ from a distance of $15 \mathrm{~m}$. However, in both cases, in spite of these devices obtaining good results, they are both expensive to install, time consuming for data interpretation, and susceptible to being easily manipulated or even stolen.

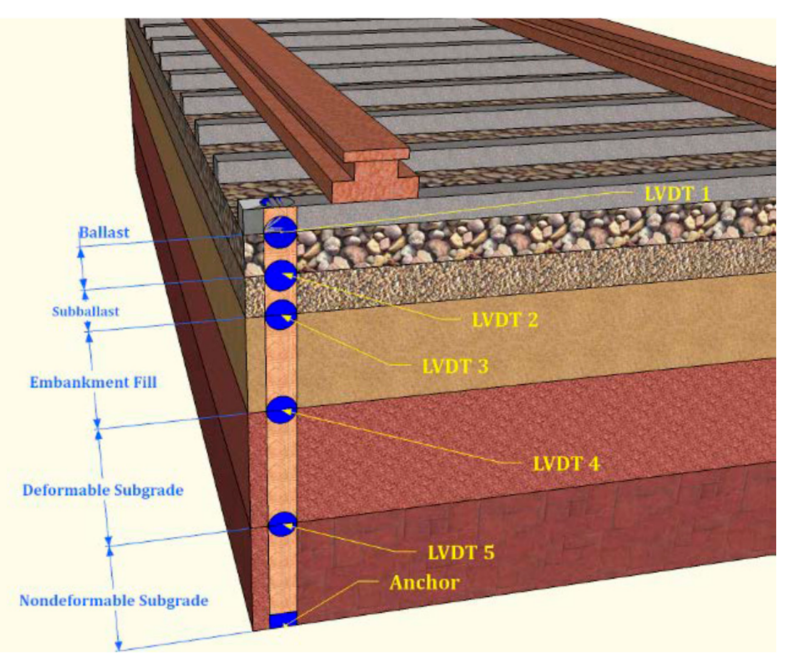

Figure 1. Schematic of track substructure used by Mishra et al. [13].

\subsection{Component Fatigue Failure}

Another factor that could significantly affect rail track operability is the fatigue failure of individual components. With increasing load capacities (freight trains) and speeds (passenger trains), the rail could suffer located defects due to the dynamic impacts received, where any irregular wheel-rail contact and slips between the wheels and rail would promote extra short-wave vibrations, as well as an increase in stresses. The railroad fasteners are also subjected to fatigue efforts due to cyclic elastic movements, further increasing with force-wave transmission and any noise from wheel-rail contact. 
In the sleepers, also affected by the passing train, different defects could appear depending on the material with which they are manufactured. In timber sleepers, bio-deteriorations and the climate affect them considerably $[15,16]$. On the other hand, concrete sleepers are mainly affected by wheel-rail impacts as well as rail-seat deterioration caused by frictional forces present between the pads and the sleepers, further increasing with the presence of any fine particles and/or water [17,18].

Regarding the ballast layer, its degradation can be associated with the abrasion between the corners of the aggregates or its crushing due to traffic overloads, along with ballast fouling, due to any fine particles that considerably affect water drainage, negatively influencing rail track stiffness regularity [19]. Aggregate degradation could be caused by climatic factors and freeze-thaw cycles [20], but mainly from the breaking of aggregates due to the passing traffic [21]. The variation in stiffness along the railway track induces a dynamic load between wheel-rail contact and sleeper-ballast, further increasing the fatigue problems in the rest of components [22], while also varying the bearing capacity of the track. Additionally, high overloading in the sleepers and ballast increases the settlement that could appear in the railroad structure.

Therefore, to minimize the degradation of the various components, it is essential to control and monitor the forces transmitted by the train to the track, as well as evaluate the evolution of the bearing capacity of the track and its deformations. To date, corrective maintenance has been mainly carried out for these components, detected through a visual exam carried out by a specialist or in some cases, with the aid of auscultators trains. However, with the applications of new technology systems is could be possible to detect this type of failure sooner-for example, through the use of axle-box acceleration analysis [23] or analyzing the displacement, accelerations and velocities via the electromagnetic waves in rails and sleepers [19].

\subsection{Vibration and Noise}

Among the more direct results of rail track settlements and fatigue failures are the deformations and irregularities along the track, which increase vibrations and noise levels. This problem is especially relevant in urbanized areas. According to Connolly et al. [24], there are two main track imperfections that contribute to track vibrations: (a) repeated loading at high frequencies, which can deform the wheels causing the loss of its initial geometry [25], and (b) the appearance of irregularities in the rail due to impacts or deformations associated with problems such as stiffness changes, settlements, welding, transition zones or excessive wear [26]. There are numerous mechanisms that influence rail track vibrations, which have a certain frequency whose ranges can be observed in Figure 2.

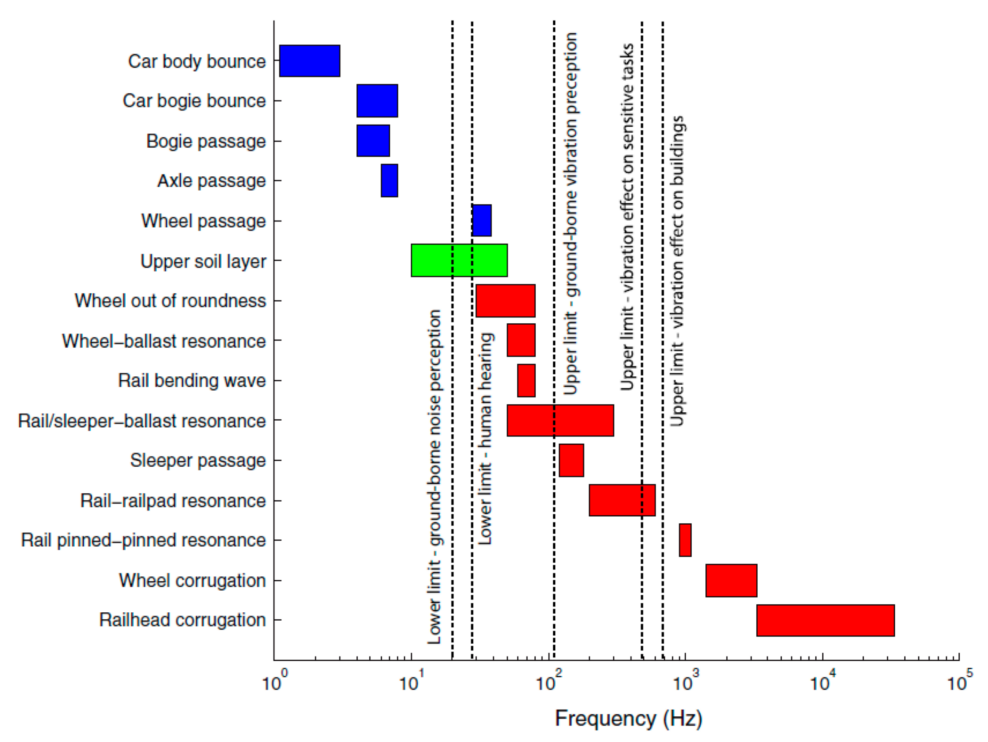

Figure 2. Typical frequency range excitation [24]. 
Furthermore, it is important to note during the monitoring of the track that throughout the noise (or vibration) spectrum, it is possible to predict the rail-sleeper-force [27], and therefore, it is possible to identify specific track failure types, and thus, the corresponding preventive maintenance operation. For this reason, a good knowledge of the vibrations (amplitudes and frequencies) makes it possible to identify specific problems on the rail track system, as well as quantify them. Traditionally, these vibrations are recorded with the help of accelerometers implanted in the auscultator trains.

\subsection{Change in the Structural Section Influence of Stiffness}

As mentioned above, the changes in the rail track's stiffness play a crucial role in the proper performance of the railroad. Given both the current and anticipated future trends for traffic (faster and higher loaded trains), a more rapid degradation of components is to be expected, particularly in the case of the ballast since this can be considered the weakest component in ballasted tracks (the most common track type). These facts cause stiffness variation in the rail track section, further accentuating its effect. A higher stiffness gives place to higher overloads in the rail track, causing corrugation and increasing the vibrations [28]. Meanwhile, a low stiffness directly influences the increase in ballast settlement and the fatigue of components [29]. This also increases the necessary power for the locomotives to cross the track, and thus, the level of vibration and noise. Nielsen showed that vertical stiffness variations induce differential track settlements, resulting in the accelerated deterioration of the railway track [30]. In addition, track stiffness considerably influences track geometry deterioration, rail fatigue and the deterioration of other components of the railway [31].

Figure 3 shows an example of how a difference between the stiffness that there is in the railway track and its optimum could cause a high vertical track geometry deterioration.

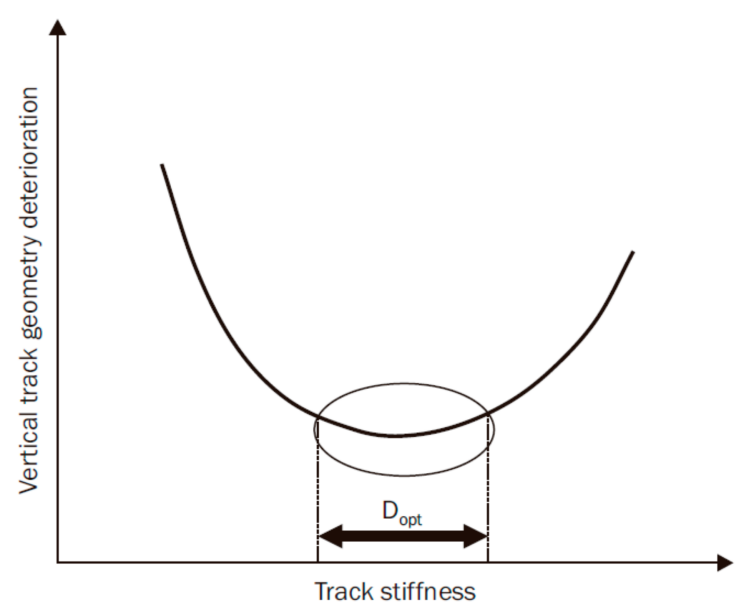

Figure 3. Illustrative display of optimum track stiffness [31].

For this reason, it is necessary to guarantee good stiffness regularity throughout the railway track, and hence, incorporate real-time continuous monitorization. Traditionally, the rail track stiffness is measured with a rail car system that applies a load and measures the track deformation. The China Academy of Railway Sciences (CARS) was among the first to develop a vehicle for the continuous measurement of the static stiffness. Since then, these type of devices have been developed in different countries, such as TU Delft's High Speed Deflectograph (HSD) in the Netherlands [32], Track Loading Vehicle (TLV) in the USA [33], Rolling Stiffness Measurement Vehicle (RSMV) in Sweden, Szybka Kolej Miejska w Trójmieście (SKMT) device developed by the Czech Technical University of Prague and the Commercial Railway Research Ltd. (KZV) in Czech Republic or Schweizerische Budesbahnen (SBB) in Switzerland [34]. However, all of these methods require track closure while the measurements are taken, and thus further increase the associated maintenance cost [35]. In addition, a limitation of these systems is that they do not provide the stiffness variation along the whole railway line. 
Nowadays, there are other techniques to measure track stiffness, from the traditional hydraulic jack-loading methods, by applying a certain amount of load on the rail and measuring the displacement with a displacement meter [35], to the more sophisticated methods, using fiber optics [36-38], which still need to be developed in greater depth.

\section{Monitoring Elements}

Having covered the traditional failure modes and their traditional monitoring methods, this section will review the currently available sensor solutions. Within the different technologies available, this paper analyzes those that would allow the real-time and continuous monitoring of the rail track condition, instead of how it is currently conducted in a periodic manner.

\subsection{Strain Gauges}

\subsubsection{Main Characteristics}

Strain gauges are a type of sensor able to measure micro-deformations through its piezo-resistive properties. Piezo resistive properties provide a material with the capability to change electrical resistance when a certain load or pressure is applied to its surface, deforming it in the mechanical-axis directions. Thus, in the case of the strain gauges, as the length of the material increases, its resistivity decreases due to the reduction in the cross-section [39]. It is necessary to determine the elastic modulus of the gauge, due to the fact that it is not possible to use it outside of its elastic limits.

Typically, the strain gauge is manufactured with a metallic foil pattern which is formed by photoengraving a film that has previously been mounted onto a flexible resin plastic base [40]. The dimensions of metallic gauges can vary between 0.4 and $150 \mathrm{~mm}$, and its resistance between 120 and $350 \Omega$. Specialized gauges are also available with a resistance of $1000 \Omega$, specially designed to be used with polymer materials [41]. Gauges are able to register micro-deformations around 0.005 . Normally, these devices require a voltage of 2 to $20 \mathrm{~V}$, and through measuring their change in electrical properties the deformation in the material can be calculated.

In the market, it is possible to find a multitude of strain gauge types, from gauges designed to be glued over a surface (i.e., on a rail or a sleeper), to gauges to be embedded into a material (i.e., in concrete or bituminous mixtures). With little changes in resistance it is possible to detect applied loads, but readings are highly susceptible to temperature changes; thus, the Wheatstone bridge (Figure 4) is typically adopted for its assembly. This arrangement is formed by 4 resistors, which increase the sensitivity of the sensor, while compensating the undesired effect of its temperature sensitivity [42].

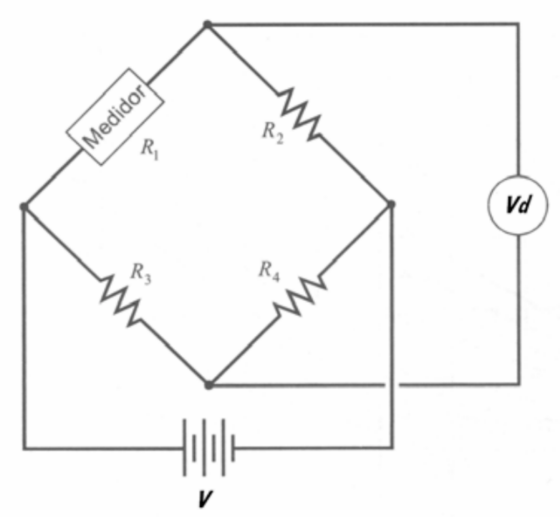

Figure 4. Example of Wheatstone bridge, where medidor refers to the strain gauge [42].

Strain gauge sensors were initially considered as a good way to detect dynamic loads and train speeds, by determining the deformation of a rail due to a passing train, which could also monitor the 
bearing capacity of the track and the deformation of its components. Nonetheless, it must be considered that they present certain disadvantages that are necessary to take into account such as its fragility, susceptibility to electromagnetic interference, excessive size and high sensitivity to temperature [12].

\subsubsection{Case Studies}

Most application of gauges are based on the hypothesis that the forces identified in rails could be considered as an indicator of the vehicle type on the rail. It is possible to characterize the forces through the deformations that occur from passing trains, via determining the strain measured and the properties of the material (i.e., Young's modulus E and Poisson ratio). Gauge positions play a fundamental role in data collection. An example of sensor setup is shown in Figure 5, where a sensor with four gauges, oriented at $45^{\circ}(a, b, c, d)$, is positioned in the neutral axis of the rail's web to determine the vertical loading, P. Additionally, it is possible to measure the lateral shear force using two gauges (e and f) arranged with a vertical layout.

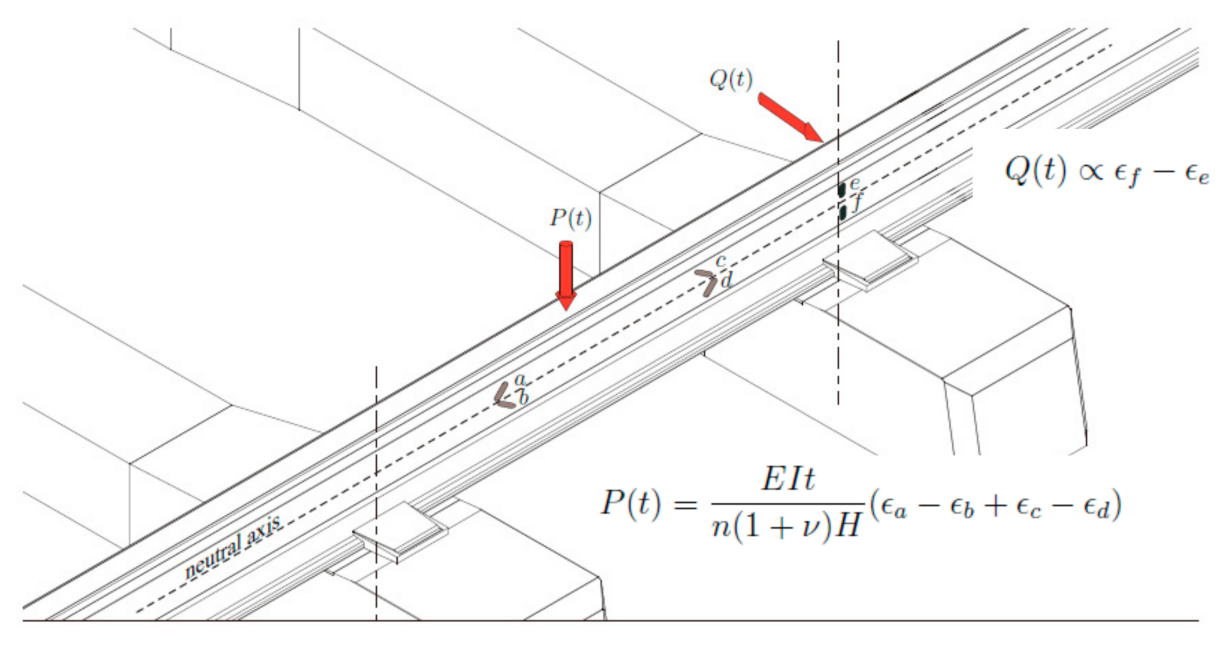

Figure 5. Gauges distribution to obtain forces $P$ and $Q$ [12].

Following this described layout, Askarinejad et al. [43] used strain gauges to detect the dynamic loads imposed by a train passing over insulated rail joints. Furthermore, Palo et al. [44] used strain distribution monitoring at the wheel/rail interference for decision-making support. However, these studies found that it was difficult to measure the forces because the data measuring period was not long enough, so that during the experiment there was not a linear wear pattern, and the trains which passed were different in nature causing different lateral forces. Other authors [45] used strain gauges to develop a new creep measurement technique by measuring internal rail stresses, considering the variation of rail temperature and the influence of straight and curved rails. Furthermore, the Multi-Purpose Q and Y load detector (MPQY) system developed by Delprete et al. [46] allowed the simultaneous measurement of the vertical forces (due to train weight), the lateral forces (primarily caused by dynamic and cinematic effects) and also, the longitudinal forces (generated by traction or braking actions) using strain gauges glued in an intermediate device, shown in Figure 6. 


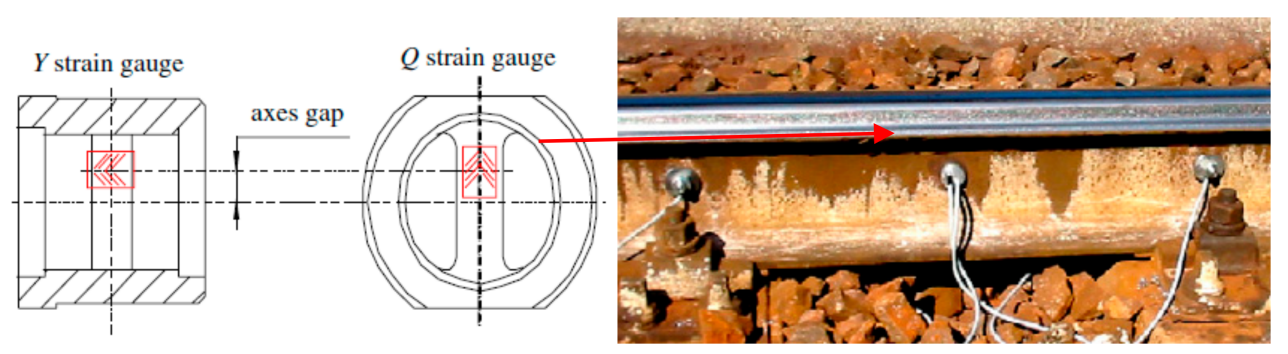

Figure 6. Multi-Purpose $Q$ and $Y$ load detector (MPQY) systems schema [46].

Conversely, INNOtec Systems GmbH, in Germany, developed the MONY system. This system uses pads equipped with force gauges in the middle, as is displayed in Figure 7. The MONY system can measure dynamic loads by obtaining a good relation between the tread state, the rail-sleeper-force and the radiated noise [27].
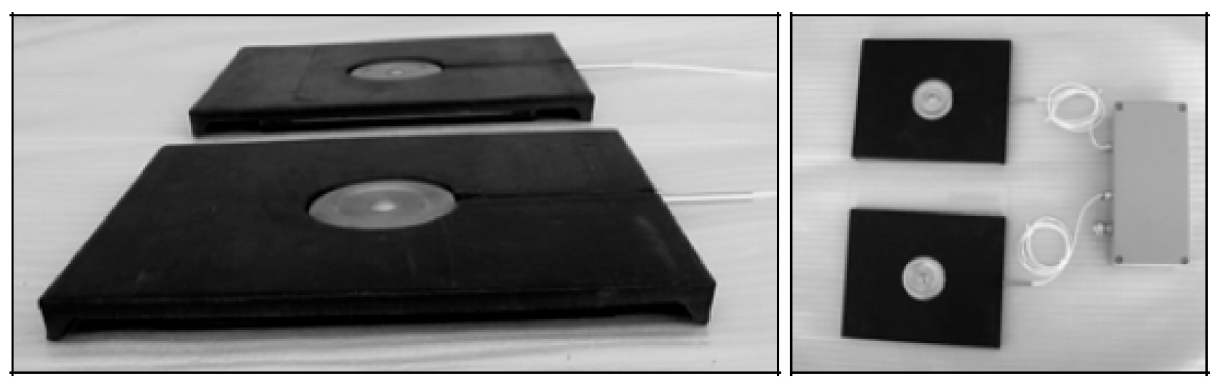

Figure 7. $\mathrm{MONI}^{\circledR}$ measurement system [27].

Finally, there are also specific gauges (H-gauges) designed to be embedded in asphalt mixtures for bituminous sub-ballast. These H-gauges were used by Khairallah et al. [47] in order to determine the deformation that appeared in a bituminous layer located in an experimental section in the line Bretagne-Pays de la Loire, France. This is a high-speed line in which two different substructures were studied: bituminous and granular sublayers. This type of gauge has two anchors that register the movement in a single axis between two points in the asphalt mixture, as is showed in Figure 8 . Additionally, this type of gauge is prepared to support the typical temperature and compaction loads of the asphalt mixture installation (reaching up to $160^{\circ} \mathrm{C}$ ).

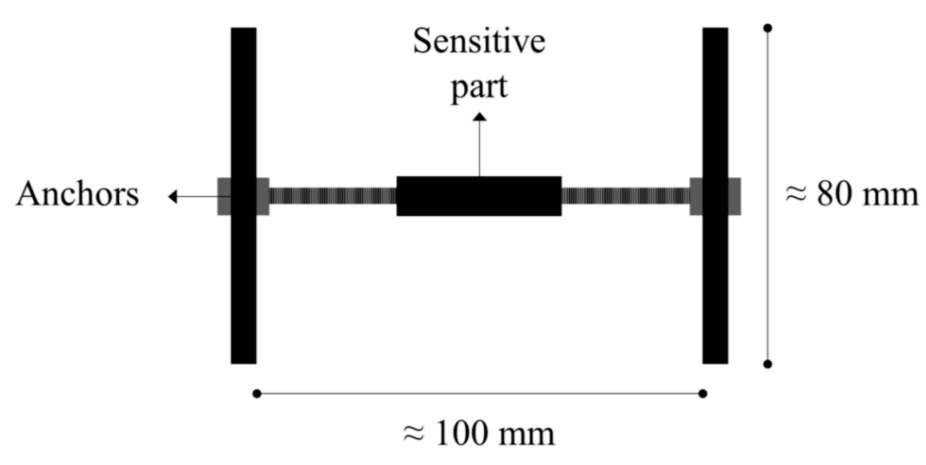

Figure 8. Schematics of a H-gauge [48]. 


\subsection{Piezoelectric Sensors}

\subsubsection{Main Characteristics}

The piezoelectric phenomenon, occurring in certain materials, consists of the capacity to generate an electric current as a result of a mechanical load or vibration. This can occur in certain naturally occurring materials such as quartz, Rochelle salt, tourmaline or topaz. Alternatively, these materials can also be synthetically produced. Among them, there is Lead Zirconate titanate (PZT), Polyvinylidene Fluoride Polymer (PVDF), Barium titanate and Zinc oxide. All of them have the capacity to generate a certain voltage when a compression load or vibration is applied. Furthermore, these types of materials, when in sensors, have a high accuracy due to their natural frequency being very high and having a good linearity in a wide range.

Piezoelectric sensors are available on the market in a wide range of types, ranging from smaller ones with a $20 \mathrm{~mm}$ diameter, all the way to large sheets with varying geometries. A piezoelectric sensor has the capacity to generate voltages in the range of a few milli-volts to tens of volts, depending on its construction. A disadvantage of their use is that it cannot be used to take a static reading, since they are activated by the variation of the compression load.

These sensors have many different uses in different fields, such as for hydraulic pressure measurement or in load cells. Meanwhile, in railway tracks, they could be used to monitor the stresses transmitted by the traffic to the rail structure, and therefore, identify any failure modes depending on the magnitude of the amplitude and frequency recorded for the track oscillations. Nonetheless, to date, in the railway field, few experiences have been reported, which shows that there is potential to further deepen this research field.

\subsubsection{Case Studies}

Zhan et al. [49] developed a monitoring rail pad to detect damage caused by train wheels, which functions by measuring the vertical forces that act on the rail pads. To achieve this, they made a rail pad with a thin PVDF-based (polyvinylidene fluoride) multilayer sensing device under the rail pads. This type of material presents certain advantages as it has a large frequency bandwidth, a linear output over a wide dynamic range, is lightweight, flexible, available in large sheet, and is also relatively low in cost (around EUR 25 for each pad sensor). The calibration of this sensor was carried out by applying series of loads from 10 to $80 \mathrm{kN}$, obtaining a maximum voltage of $6 \mathrm{~V}$. This device is shown in Figure 9 .

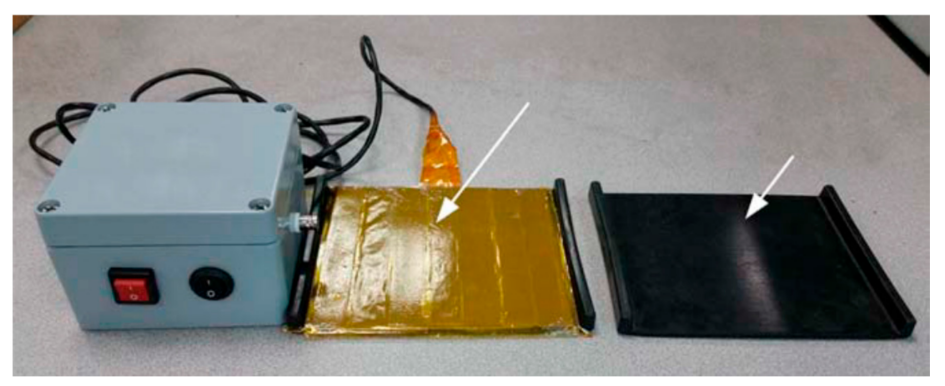

Figure 9. Signal conditioner, rail pad sensor and rail pad [49].

\subsection{Fiber-Optic Sensor}

\subsubsection{Main Characteristics}

Fiber optic sensors are based on the detection of variations of light-wave propagation in optical fibers, which are characterized by being able to span long distances and offer a long-term solution [38]. For measuring strain, fiber optic systems could be divided in two main categories (Table 1): fiber Bragg grating (FBG) sensors, where an optical interrogator is used to analyze an array of optical sensors inscribed into a fiber; a distributed optical fiber sensor (Brillion and Rayleigh scattering), where the 
optical fiber is used as a continuous sensor by itself [37]. Despite fiber Bragg gratins (FBG) having numerous advantages, thanks to their versatility, wide dynamic range and high measurement accuracy, it is only implementable in lengths of less than $1 \mathrm{~km}$. Although FBG cannot provide a continuous map of temperature or strain, within them, around 100 sensors can be found, which could be implemented with a spatial resolution of $2 \mathrm{~mm}$ [50]. However, the distributed sensors do not present this problem, allowing it to be provided [51]. Meanwhile, the distributed optical fiber sensor has the potential to span various kilometers using low cost telecommunication fibers [52]. In railway monitoring case studies, it is possible to find the latter fiber optic type (i.e., based on Brillouin and Rayleigh scattering) having been used.

Table 1. Comparison of various fiber optic sensing techniques applied to railway.

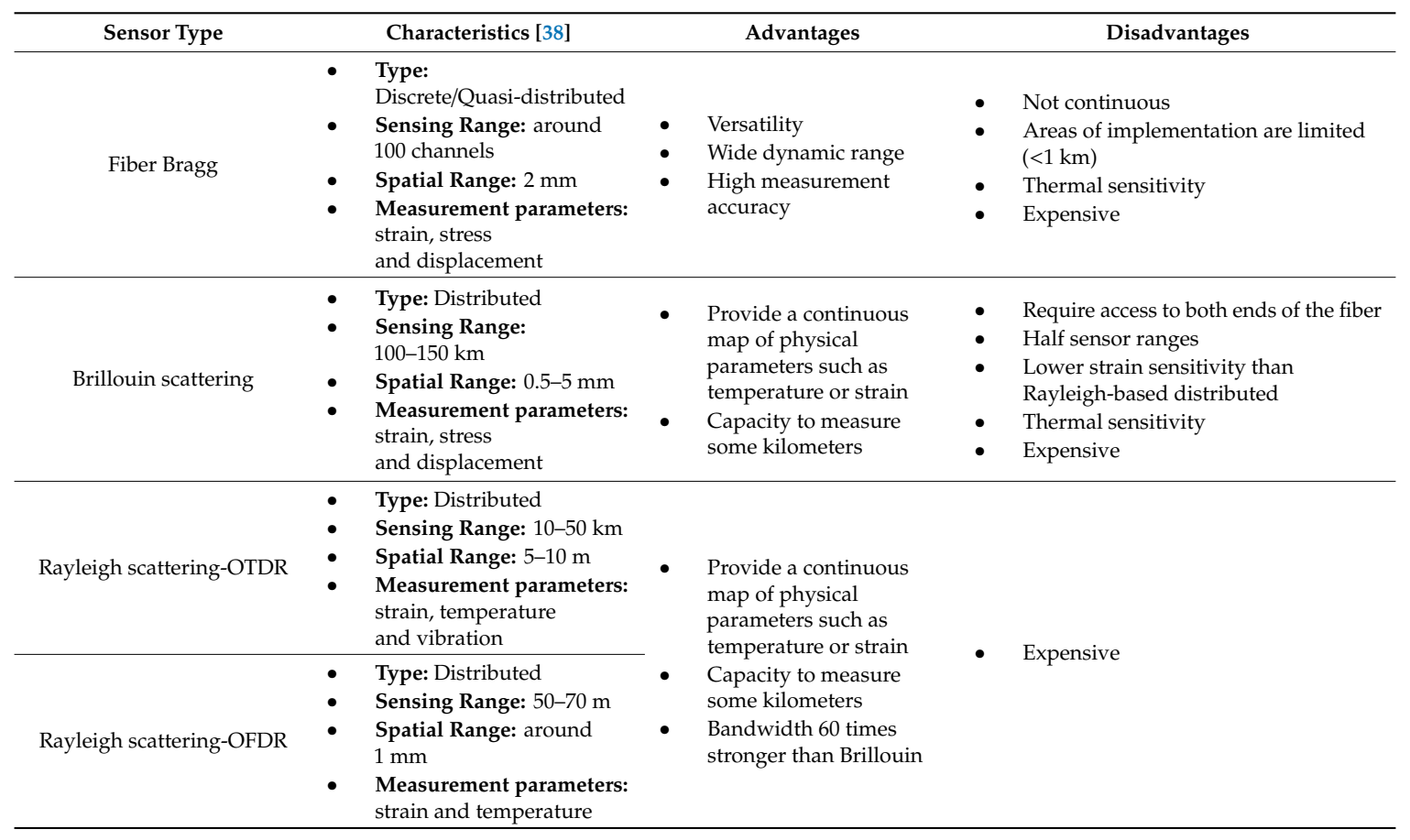

Sensors based on Brillouin scattering have the capability to provide information, such as axle counts, axle distance and train speeds, while also allowing for dynamic load estimations that could be used to understand the evolution of track degradation for preventive maintenance measures. However, this system requires access to both ends of the fiber, reducing the sensing range by half. Furthermore, this type of sensor has a lower strain sensitivity than Rayleigh-based fibers [53].

With this last scattering mode, it is possible to measure within a sensing range of 100 to $150 \mathrm{~km}$ [54] and a spatial resolution of 0.5 to $5 \mathrm{~mm}$ [55]. Moreover, in a Rayleigh-based distributed system, the acquisition bandwidth is 60 times stronger than the Brillouin scattering [56]. Within this typology, two different measurement technologies are available. The Optical Time Domain Reflectometer (OTDR) allows the measurement of the optical fiber length and characterization of the different anomalies or possible changes that appear along the fiber, such as strain, temperature and vibration changes. With OTDR, is possible to measure a sensing range between 10 and $50 \mathrm{~km}$ [57] using a spatial resolution of 5 to $10 \mathrm{~m}$ [58]. On other hand, the Optical Frequency Domain Reflectometer (OFDR) allows strain and temperature to be obtained with a sensing range much lower than OTDR (50-70 m) [59] with a spatial resolution around $1 \mathrm{~mm}[60]$.

In general, fiber optic sensors present certain advantages such as high temperature capacity, multiplexing and no sensitivity to electromagnetic interferences [12]. 


\subsubsection{Case Studies}

The first time that FBG was used in railway monitoring was in 2004, when this technology was used for axle counting and derailment detection [61]. From then on, this technology was developed in other areas of the railway, such as train wheel condition monitoring [62-64], train vibration and weight measurements [62-65] and the structural analysis of the railway track [5,66-68].

Sensorline developed a combination of several FBG sensors embedded into an elastic pad during the production process, allowing strain measurements to be obtained inside an elastic pad during the passage of trains as a base for material optimization [36], as shown in Figure 10. This sensor is used for counting train axles or recording dynamic loads, as well as for obtaining a better understanding of the strain variations in a pad to improve its replacement interval.

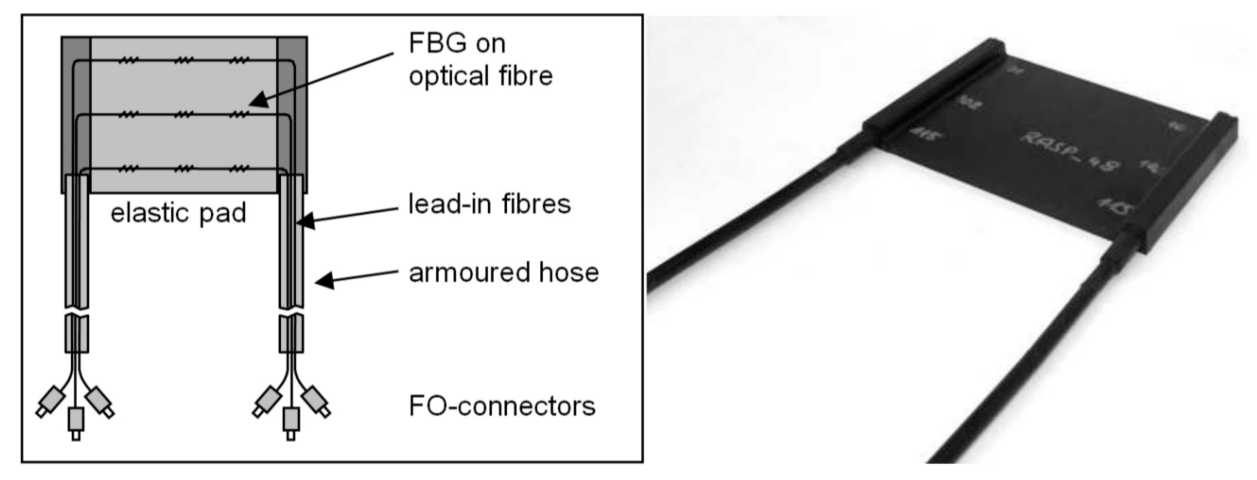

Figure 10. Schema and prototype of the rail-strain-pad [36].

Yoon et al. [69] developed another system based on the Brillouin correlation domain analysis to measure the longitudinal strain of a rail in real time, whose implementation is shown in Figure 11. On the other hand, Minardo et al. [53] used a Brillouin distributed sensor to obtain useful information, such as train identification, axle count, travel speed and dynamic load magnitude. This solution was implemented on the Italian regional line San Severo-Peschici, Italy, operated by Ferrovie del Gargano.

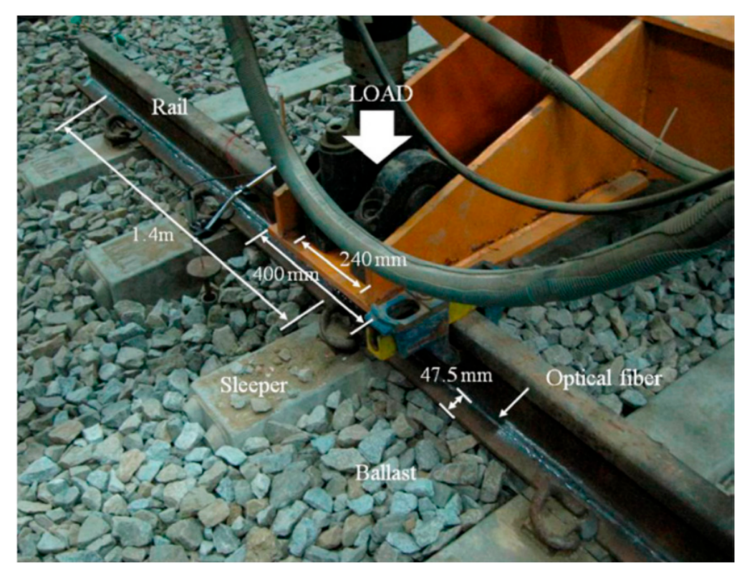

Figure 11. Schema of system developed by Yoon et al. [70].

Wheeler et al. [70] used a $7.5 \mathrm{~m}$ long rail section with an optical fiber to measure the strain during the passage of a freight train. However, despite Rayleigh backscatter fiber optic sensing allowing the measurement of dynamic strains, this measurement should be carried out at low speeds $(8-11 \mathrm{~km} / \mathrm{h})$ due to this technology being highly sensitive to vibrations, hence limiting its use. 


\subsection{Geophone}

\subsubsection{Main Characteristics}

Geophones are small seismic sensors that produce an output voltage proportional to its wave velocity when it vibrates [14]. The dynamic deflections and component movements are calculated by filtering and processing the velocities measured. Geophones have the capacity to only monitor frequencies higher than their natural frequency, up to a maximum known as spurious frequency. Commonly, the natural frequency of these devices is an order of $10 \mathrm{~Hz}$, and the spurious frequency an order of $250 \mathrm{~Hz}$ [41], although it is possible to find geophones on the market with lower natural frequencies. For example, for LF 24 (among the most commonly used), the required voltage can vary between \pm 11 and $\pm 25 \mathrm{~V}$ DC with a current from \pm 2 to $\pm 6 \mathrm{~mA}$. Additionally, the sensitivity of the geophones can range from 10 to $200 \mathrm{~V} / \mathrm{m} / \mathrm{s}$. These devices present certain advantages such as their ability to measure large displacements (in millimeters) and being easily powered [35].

\subsubsection{Case Studies}

LF 24 (Low frequency velocity sensor) geophones were used by Bowness et al. [14] to measure peak to peak displacements (within $0.07 \mathrm{~mm}$ ) for frequencies as low as $1 \mathrm{~Hz}$ in the sleepers. Milne et al. [71] used the same type of geophone to carry out a comparative study between LF 24 and Micro Electrical Mechanical System accelerometers, which showed little variations in their results. Figure 12 shows the accelerometer and the geophone setup over a sleeper, which are used to register the accelerations produced by the passing trains.

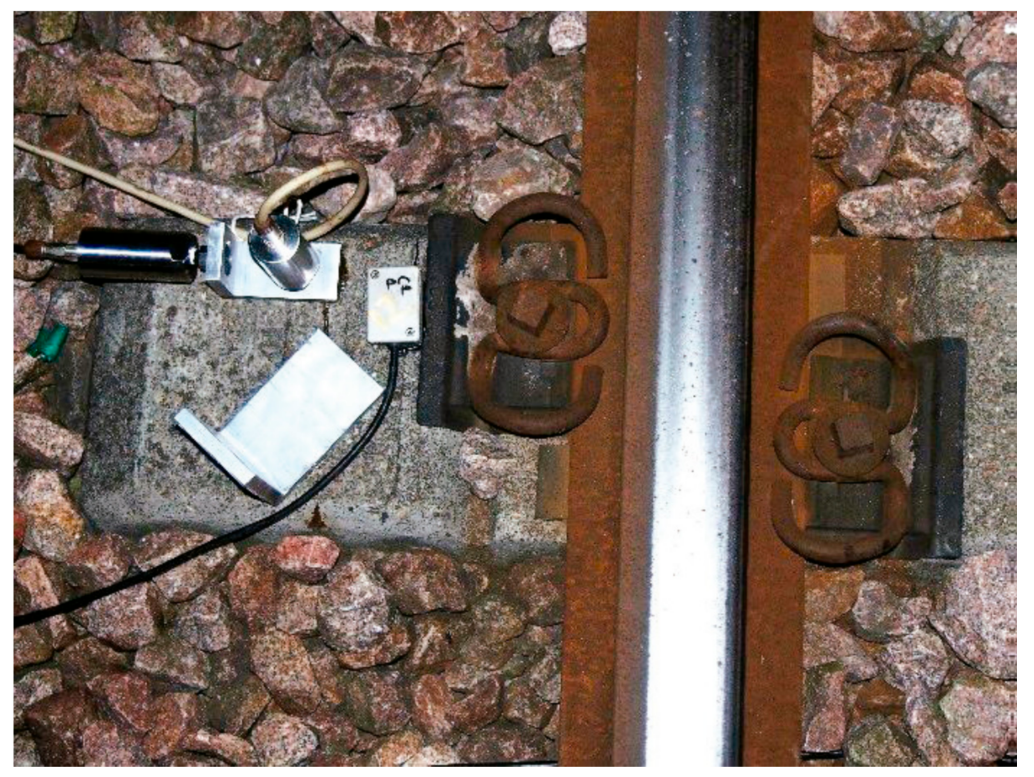

Figure 12. Accelerometer and geophone glued to the sleeper [72].

Crespo-Chacon et al. [72] obtained reliable readings for the vertical velocities and displacements of vibrating rails on the high-speed line that connects Madrid with Valladolid, Spain, through the use of $2 \mathrm{~Hz}$ geophones. To obtain reliable measurements when the train speeds were lower than $100 \mathrm{~km} / \mathrm{h}$, different corrections (phase and amplitude) were applied.

\subsection{Accelerometer}

\subsubsection{Main Characteristics}

Accelerometers, depending on their structure and operation, can be divided in two main types: piezo-resistive and capacitive based accelerometers [73]. In the piezo-resistive accelerometers, vibrations 
are detected and transformed into a voltage by a piezoelectric cantilever, a membrane or a thin film [74]. In contrast, capacitive sensors record acceleration changes between a slightly separated proof mass and a conductive electrode [73]. The typical operation frequency can be from 2 to $10 \mathrm{kHz}$, measuring accelerations that can vary between \pm 1 and $\pm 250 \mathrm{~g}$. Accelerometers are usually a low potency device, using an electrical current of the order of a micro-amp or a milli-amp, and a voltage of the order of $5 \mathrm{~V}$ or less.

In recent years, micro-electrical mechanical systems (MEMS) are also being developed. These are small-size, low-cost sensors used to measure accelerations. Typically, the sensors are embedded in a semiconducting chip. The cost of this type of accelerometer (considering the price of the cheapest, commercially available, conventional accelerometer (together with the signal conditioning unit)) can be around $1 \%$ to $10 \%$ [74] of a more sophisticated sensor, such as a geophone [71]. This type of accelerometer presents several advantages, as they are cheaper, capable of withstanding shock, have a good frequency response, need a low power input and produce little signal noise [41].

\subsubsection{Case Studies}

Khairallah et al. [47] used accelerometers to measure the vertical dynamic behavior of a railway track. To achieve this, accelerometers were placed under a sleeper and at the top of a bituminous sub-ballast layer with the aim to compare the differences in levels acceleration between a conventional section and a section with a bituminous sub-ballast layer.

Milne et al. [71] demonstrated how MEMS can be used to successfully obtain displacements from acceleration data measurements, through a double filter-integration. The accelerometers tested were the ADXL335 and ADXL326, whose results were compared with those obtained with a geophone (a relatively more expensive sensor, as stated previously). Given that railway track deformations occur at low frequencies, high frequencies are less important for track monitoring, and thus can be filtered out with a low pass filter [14]. Both the accelerometers and the geophone were glued to the same sleeper as shown in Figure 12. Although this sensor type could output a noisier signal, it was found to be of sufficient quality to be used to obtain track displacements and quantify trends in track behavior.

From the results of the case studies considered, if accelerometers and geophones are compared, it is possible to see that in spite of the geophones having a higher precision than the accelerometers, they are more expensive. Furthermore, accelerometers have a sufficient resolution to be used in railway tracks to measure accelerations and displacements, and they are less frequency-limited, compared to the geophones, which cannot operate below their natural frequency. Table 2 summarizes the main similarities and differences between these types of sensors.

Table 2. Comparison between geophones and accelerometers.

\begin{tabular}{ccc}
\hline Characteristics & Geophone & Accelerometers \\
\hline Acceleration and displacement measurement & $\checkmark$ & $\checkmark$ \\
Relatively low cost & & $\checkmark$ \\
High frequency range operation & & $\checkmark$ \\
High signal noise & $\checkmark$ & \\
High measurement precision & $\checkmark$ & \\
\hline
\end{tabular}

\section{Discussion}

According to the aforementioned results, there are many sensors that offer the capability to be embedded in railway infrastructure, and that through their use it is possible to continually monitor the development of rail track failures. For this purpose, it is necessary to clarify which sensors are applicable to which failure type.

Assessing the data in Figure 13, in agreement with the case studies analyzed in the literature available, it is seen that permanent deformations have been traditionally evaluated through the direct measurement of the evolution of permanent or plastic deformations of the track bed under the passage 
of trains [29]. However, it must be noted that most of the previous research focused on temporally and geographically specific case studies, and therefore, would require devices with the ability to control such parameters through time and along the railway $[13,22]$. Similarly, this also happens when monitoring the transmission of vibrations, finding punctual investigations into specific problems related to this issue, using specialized instrumentation for punctual studies mainly measuring vibrations along the ground $[68,69]$.
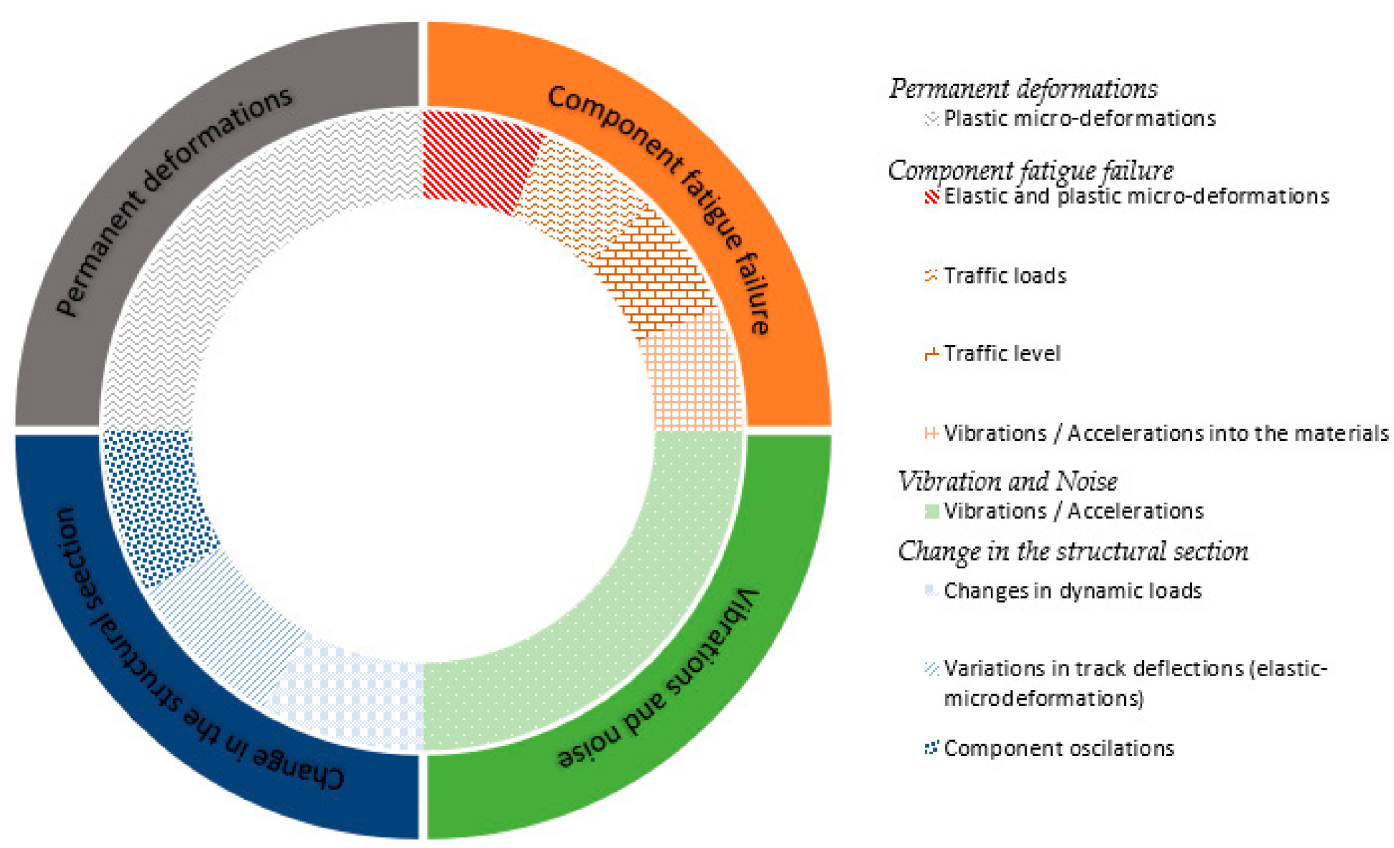

Figure 13. Variables to consider to monitor the main rail track failure modes.

On the other hand, results show that the changes in the structural response of the track (such as changes in track stiffness, also influencing the previously cited failure modes) could be monitored through the measurement of different parameters, highlighting the variations in component oscillations (such as sleeper movements) or global track deflections over the rail [24], as well as measuring the variations in the dynamic loads generated from wheel-rail interaction or impacts between the sleeper and ballast. Nonetheless, despite all these possibilities, traditional monitoring of these issues has focused on complex solutions, mainly applying loads over the rail and measuring track deflections with special vehicles [32-35]. Therefore, it could be interesting to design and implement smart sensors, with the capability to measure these properties continuously in real-time, to monitor the loads applied by traffic and quantify track deflections or oscillations and to avoid train line closures for structural health assessment.

In the same way, devices with the capacity to measure elastic and permanent micro-deformations in materials would monitor the evolution of the performance of components, which would also assist in monitoring the global track response. For the characterization of the life of the components, it would also be necessary to measure traffic conditions (load magnitude and frequency) that could modify the fatigue resistance of such components [28-31]. Furthermore, in previous years, the monitoring of material structure and state through the measurement of wave propagation into the components is gaining importance, requiring small and tailored devices to be included into the materials.

Therefore, it is seen that there are many sensor types available for continuous monitoring. However, not all sensors have the capability of measuring elastic and permanent micro-deformations. In this study, strain gauges, piezoelectric sensors, optical fibers, geophones and accelerometers have been considered since they were found to have been previously used for railway monitoring in the literature review. The placement of these sensors will depend on the variable that needs to be measured. 
Figure 14 represents the placement options for the different sensors usable for continuous monitoring, while Figure 15 relates the main variables that could be measured with each sensor to their relative cost per lineal meter of infrastructure.

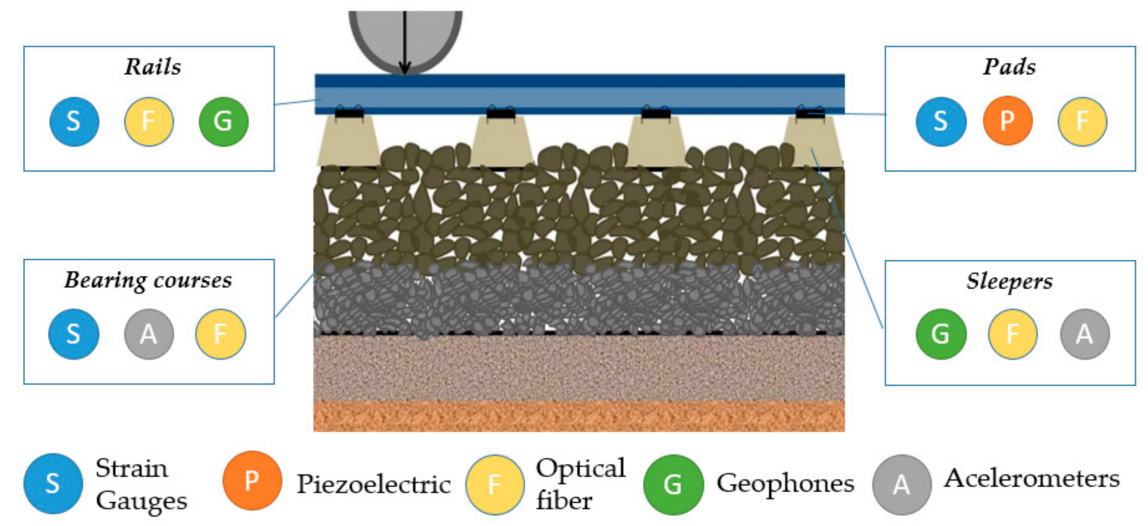

Figure 14. Sensor placements in the case studies reviewed.

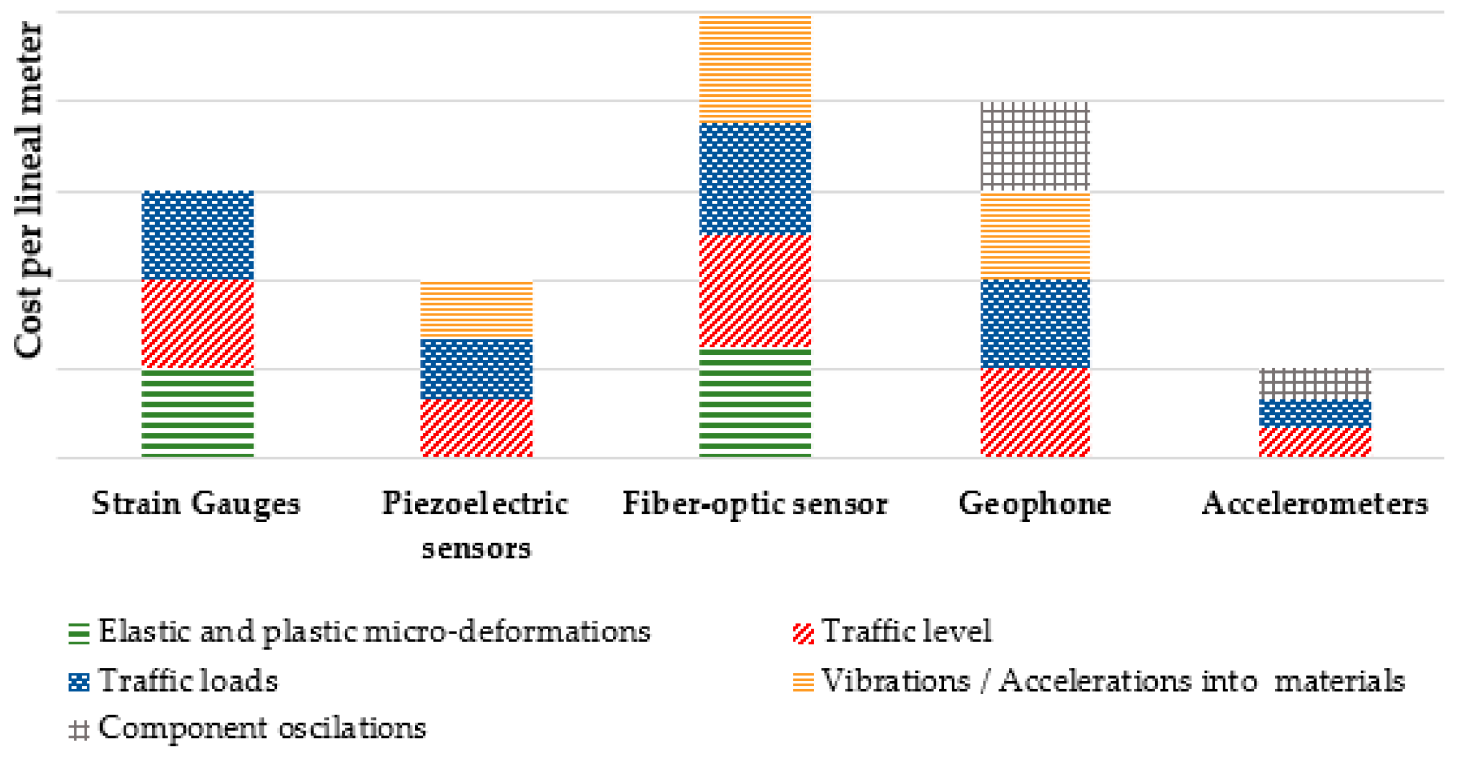

Figure 15. Difference in terms of cost per lineal meter and the main variables measured by each sensor.

While strain gauges have been widely used in rails, pads and bearing courses to measure elastic and plastic micro-deformations at a reasonable cost (in comparison with the other sensors), its application in sleepers could also be a viable way to measure the performance of this component and the evolution of its fatigue life. Nonetheless, it must be considered that this application has not been studied to date, and therefore, further study will be required [27,43-47]. Additionally, although these micro-deformations are normally correlated with fatigue failure, a strain gauge would also be able to identify other failures in an indirect way, such as traffic loads [43], by correlating the strain measured with the stress applied by using the Young's modulus and Poisson ratio of the material. Furthermore, as it happens with all sensors, traffic conditions could be measured by considering the number of oscillations generated by the sensor (axel counting) or the time between two consecutive sensor readings along the railroad (train speed). Nonetheless, it must be kept in mind that strain gauges are affected by electromagnetic interferences when measuring the deformations, as opposed to 
the fiber-optic sensor, which reflects that this technology could be an interesting alternative to strain gauges [12,75].

Regarding piezolectric sensors, although they have demonstrated the potential to measure dynamic loads with a good linearity and a large bandwidth at a low price, there are not many case studies demonstrating their use [46]. However, this sensor could be a suitable solution for measuring different parameters, such as the loads transmitted by the trains and the vibrations of the railroad materials [49]. This could allow the monitoring of the number of trains that pass and their weight, as well as track performance such as bearing capacity or changes in track stiffness through determining if the components vibrate more in one section of the track than in other areas. Furthermore, as has been conducted in other fields, piezoelectrics could be studied for their application to detect fatigue failures of materials due to sudden changes in electric pulses generated. For all these purposes, it would be necessary to develop this technology, adapting it to the place where it going to be and also, encapsuling it when necessary to guarantee its operability. Therefore, despite the fact that further studies are still required before its wide application, these sensors show great potential due to their versatility and low cost.

In the same way, it is seen that the optical fiber sensor can be considered rather versatile, although its price is commonly higher than piezoelectrics. Nonetheless, due to such versatility, combined with the high development of this technology in the last years, this type of sensor has started to be used for railway monitoring, showing a great potential for its implementation in different parts of the section (Figure 14). Nowadays, there are studies that implement this technology in rails, pads, sleepers and also in bearing courses [34]. Furthermore, it presents certain advantages as it is immune to electromagnetic interference (which is present in railway lines and cannot be eliminated [75]), and it is the only sensor (studied in this review) that could measure temperature changes, being an important variable for understanding the longitudinal changes in the rails caused by dilation [47].

With this technology (optical fiber), it is possible to identify changes in the rail track stiffness, by identifying the change in dynamic stresses and elastic micro-deformations (Figure 13). Some of the fatigue failure modes in railroad components (such as sleeper cracking or variations in the regularity of rails) could be studied through the transmission of vibrations into materials. Additionally, in addition to identifying the deformations of components, optical fibers can be used for other applications such as axle counting, vibration measurement and wheel condition monitoring [61-70]. However, although there are studies that use this technology, there is a need for further development to make it economically more competitive.

Finally, geophones and accelerometers can both be used to measure component oscillations. From these readings, it would then be possible to identify track displacements through mathematical analysis (e.g., the double integration of the signal). If both are compared, in spite of geophones having a higher accuracy than accelerometers, the latter are more economic and precise enough for this use [49]. Through their use, it is also possible to identify changes in the rail track stiffness, due to an increase in vibrations in the readings. Additionally, through the knowledge of the vibration amplitudes of the railway's component oscillations, and their frequencies, it is possible to identify certain fatigue problems related with the train's wheels, and the infrastructure's rails and sleepers [24]. On the other hand, although both sensors register vibrations, only the geophones have the capacity to register vibrations of the materials (similar to the piezoelectric and optical fiber sensors).

\section{Conclusions}

Predictive maintenance operations carried out with novel monitoring systems would provide a more in-depth, real-time and up-to-date knowledge of the railway track condition. In turn, this would decrease maintenance costs as interventions would only be carried out when they are really needed. In this way, it would be possible to achieve smarter, more efficient and more sustainable infrastructure by reducing the resources necessary for its maintenance. In this line, through the assessment of the main technologies available for railway track monitoring, it is possible to extract the following conclusions: 
- The monitoring of the different main modes of failure of ballasted railway tracks can be carried out through advanced but simple sensors able to measure diverse parameters such as component deformations and vibrations, track oscillations and dynamic forces applied by traffic.

- In this sense, optical fiber sensors were demonstrated to be among the most versatile sensors since they can track diverse properties, such as deformations, stress levels, vibrations and temperature with a single sensor. Nonetheless, it must be considered that due to the high price of these sensors, in comparison with other alternatives, they would require further research and development to enable their widespread application.

- To cover this disadvantage, a strain gauge could be used as a simple device to track the micro-deformations in components. However, its use presents certain disadvantages, such as its fragility, while also being susceptible to electromagnetic interference and having a high dependence on temperature.

- On the other hand, it has also been seen that the state of the track could be monitored through measuring the transmission of stresses and vibrations, where various experiences demonstrated that piezoelectrics and accelerometers present a good potential for this application.

- This is especially highlighted in the case of piezoelectrics because of their diverse advantages, such as their high linearity and their low cost, while allowing for a clear recording of the dynamic loads (intensity and frequency).

- On the other hand, while piezoelectrics could be more appropriate for monitoring traffic loads, accelerometers are considered to be a promising technology to measure vibrations and deflections (to calculate stiffness changes, differential settlement, hanging sleepers, etc.) because of their high accuracy and lower prices compared to other devices, such as geophones.

- Therefore, it can be concluded that piezoelectric, accelerometer or fiber optic sensors are the most ideal for being embedded into a railway track's substructure (e.g., elastic elements, sleeper, bituminous sub ballast), while avoiding certain problems, such as stealing or vandalism.

Therefore, based on this study, it can be understood that there are currently various technologies available with the characteristics necessary for the continuous monitoring of a railway track's structural state. These sensors are capable of measuring different parameters, such as deflections, deformations, stresses or accelerations that would permit the tracking of various forms of degradation, such as railroad settlement, component fatigue, undesired vibrations or changes in the structural section. However, to continue advancing in this research line, it is essential to develop new systems, which are economically and technically viable, that could be used to support maintenance activities.

Author Contributions: Literature review and analysis, J.M.C.-M., M.S.-S., F.M.-N. and M.C.R.-G.; writing-original draft preparation, J.M.C.-M. and M.S.-S.; writing_review and editing, J.M.C.-M., F.M.-N. and M.C.R.-G. All authors have read and agreed to the published version of the manuscript.

Funding: This research received no external funding.

Conflicts of Interest: The authors declare no conflict of interest.

\section{References}

1. Eurostat, Statistical Office of the European Communities. 2020. Available online: https://ec.europa.eu/ eurostat/web/transport/data/database (accessed on 12 November 2020).

2. Mesa, L.; Palacio, I.; Martín, S.; Manzano, G.; Domínguez, J. Atlas of High Speed Rail in Spain, Madrid (España); Fundación de los Ferrocarriles Españoles: Madrid, Spain, 2017.

3. Calvo, F.; De Oña, J.; López, G.; Garach, L.; De Oña, R. Rail track costs management for efficient railway charges. Proc. Inst. Civ. Eng. Transp. 2011, 166, 325-335. [CrossRef]

4. Williams, R. Improvement in Electric-Signaling Apparatus for Railroad. U.S. Patent US130661A, August 1872.

5. Kouroussis, G.; Kinet, D.; Moeyaert, V.; Dupuy, J.; Caucheteur, C. Railway structure monitoring solutions using fibre Bragg grating sensors. Int. J. Rail Transp. 2016, 4, 135-150. [CrossRef] 
6. Brzozowski, K.; Ryguła, A.; Maczyński, A. The use of low-cost sensors for air quality analysis in road intersections. Transp. Res. Part D Transp. Environ. 2019, 77, 198-211. [CrossRef]

7. Chilamkuri, K.; Kone, V. Monitoring of varadhi road bridge using accelerometer sensor. Mater. Today Proc. 2020, 33, 367-371. [CrossRef]

8. Xue, W.; Wang, L.; Wang, D.; Druta, C. Pavement Health Monitoring System Based on an Embedded Sensing Network. J. Mater. Civ. Eng. 2014, 26, 04014072. [CrossRef]

9. Ribeiro, D.; Calçada, R.; Ferreira, J.; Martins, T. Measurement of the Dynamic Displacements of Railway Bridges Using Video Technology. Matec Web Conf. 2015, 24, 2007. [CrossRef]

10. Murray, C.A.; Take, A.; Hoult, N.A. Measurement of vertical and longitudinal rail displacements using digital image correlation. Can. Geotech. J. 2015, 52, 141-155. [CrossRef]

11. Gräbe, P.J.; Shaw, F.J. Design Life Prediction of a Heavy Haul Track Foundation. Proc. Inst. Mech. Eng. Part F J. Rail Rapid Transit 2010, 224, 337-344. [CrossRef]

12. Kouroussis, G.; Caucheteur, C.; Kinet, D.; Alexandrou, G.; Verlinden, O.; Moeyaert, V. Review of Trackside Monitoring Solutions: From Strain Gages to Optical Fibre Sensors. Sensors 2015, 15, 20115-20139. [CrossRef]

13. Mishra, D.; Tutumluer, E.; Boler, H.; Hyslip, J. Instrumentation and Performance Monitoring of Railroad Track Transitions using Multidepth Deflectometers and Strain Gauges. In Proceedings of the 93rd Annual Meeting of the Transportation Research Board, Washington, DC, USA, 15 January 2014.

14. Bowness, D.; Lock, A.C.; Powrie, W.; Priest, J.A.; Richardson, D.J. Monitoring the dynamic displacements of railway track. Proc. Inst. Mech. Eng. Part F J. Rail Rapid Transit 2007, 221, 13-22. [CrossRef]

15. Cornners, T. Producing and Inspecting Railroad Crossties; Department of Forestry, University of KentuckyCollege of Agriculture: Lexington, Kentucky, 2008.

16. Ferdous, W.; Manalo, A.C. Failures of mainline railway sleepers and suggested remedies-Review of current practice. Eng. Fail. Anal. 2014, 44, 17-35. [CrossRef]

17. Zeman, J.; Edwards, J.; Barkan, C.; Lange, D. Failure mode and effect analysis of concrete ties in North America. In Proceedings of the 9th International Heavy Haul Conference: Heavy Haul and Innovation Development, Shanghai, China, 22-25 June 2009.

18. Zi, G.; Moon, D.Y.; Lee, S.-J.; Jang, S.Y.; Yang, S.C.; Kim, S.-S. Investigation of a concrete railway sleeper failed by ice expansion. Eng. Fail. Anal. 2012, 26, 151-163. [CrossRef]

19. Uranjek, M.; Štrukelj, A.; Lenart, S.; Peruš, I. Analysis of influential parameters for accelerated degradation of ballastrailway track. Constr. Build. Mater. 2020, 261, 19938. [CrossRef]

20. Nurmikolu, A. Degradation and Frost Susceptibility of Crushed Rock Aggregates Used in Structural Layers of Railway Track; Tampere University of Technology: Tampere, Finland, 2005.

21. Indraratna, B.; Ngo, T.; Rujikiatkamjorn, C. Performance of Ballast Influenced by Deformation and Degradation: Laboratory Testing and Numerical Modeling. Int. J. Géoméch. 2020, 20, 04019138. [CrossRef]

22. Berggren, E. Railway Track Stiffness: Dynamic Measurements and Evaluation for Efficient Maintenance. Ph.D. Thesis, Royal Institute of Technology KTH, Stockholm, Sweden, 2009.

23. Tanaka, H.; Matsumot, M.; Harada, Y. Application of axle-box acceleration to track condition monitoring for rail corrugation management. In Proceedings of the 7th IET Conference on Railway Condition Monitoring 2016 (RCM 2016), Birmingham, UK, 27-28 September 2016.

24. Connolly, D.; Kouroussis, G.; Laghrouche, O.; Ho, C.; Forde, M. Benchmarking railway vibrations-Track, vehicle, ground and building effects. Constr. Build. Mater. 2015, 92, 64-81. [CrossRef]

25. Nielsen, J.; Johansson, A. Out-of-roun railway wheels- a literature survey. Proc. Inst. Mech. Eng. Part F J. Rail Rapid Transit 2000, 214, 79-91. [CrossRef]

26. Remennikov, A.M.; Kaewunruen, S. A review of loading conditions for railway track structures due to train and track vertical interaction. Struct. Control. Health Monit. 2008, 15, 207-234. [CrossRef]

27. Mueller-Boruttau, F.; Breitsamter, N.; Molzberger, H.; Buchmann, A. Detection of Brake Type and Tread Surface Quality of Passing Trains Based on Rail-Sleeper-Force Measurment. In Proceedings of the 10th International Workshop on Railway Noise, Nagahama, Japan, 18-22 October 2010.

28. Pita, A.L.; Teixeira, P.F.; Robuste, F. High speed and track deterioration: The role of vertical stiffness of the track. Proc. Inst. Mech. Eng. Part F J. Rail Rapid Transit 2004, 218, 31-40. [CrossRef]

29. Hunt, G. EUROBALT optimises ballasted track. Rail-Way Gaz. Int. 2000, 156, 813-816.

30. Nielsen, J.; Li, X. Railway track geometry degradation due to differential settlement of ballast/subgradeNumerical prediction by an iterative procedure. J. Sound Vib. 2018, 412, 441-456. [CrossRef] 
31. Puzavac, L.; Popovic, Z.; Larevic, L. Influence of track stiffness on track behavior under vertical load. Promet-Traffic Transp. 2012, 24, 405-412. [CrossRef]

32. Hildebrand, G.; Rasmussen, S. Development of High Speed Deflectograph; Road Directorate, Danish Road Institute: Roskilde, Denmark, 2002.

33. Wang, P.; Wang, L.; Chen, R.; Xu, J.; Xu, J.; Gao, M. Overview and outlook on railway track stiffness measurement. J. Mod. Transp. 2016, 24, 89-102. [CrossRef]

34. Burrow, M.; Fonsenca-Teixeira, P.; Dahlberg, T.; Berggren, E. Railway Transportation: Policies, Technology and Perspectives; Nova Science Pusblisher: Hauppauge, NY, USA, 2009; Chapter 10.

35. Vilotijević, M.; Brajović, L.; Lazarević, L.; Mirković, N. Methods for track stiffness measurement-state of the art. In Proceedings of the New Horizons 2017 of transport and communications, Doboj, Bosnia-Herzegovina, 17-18 November 2017.

36. Woschitz, H. Development of a rail-strain-pad using FBG sensors. In Proceedings of the 5th International Conference on Structural Health Monitoring of Intelligent Infrastructure (SHMII-5), Cancún, Mexico, 11-15 December 2011.

37. Milne, D.; Masoudi, A.; Ferro, E.; Watson, G.; Le Pen, L. An analysis of railway track behavior based on distributed optical fibre acoustic sensing. Mech. Syst. Signal Process. 2020, 142, 106769. [CrossRef]

38. Du, C.; Dutta, S.; Kurup, P.; Yu, T.; Wang, X. A review of railway infaestructure monitoring using fiber optic sensor. Sens. Actuators A Phys. 2020, 303, 111728. [CrossRef]

39. Ferrero, J.; Guijarro, E. Instrumentacion Electrónica. Sensores; Servicio de Publicaciones UPV: Valencia, Spain, 1994.

40. Azate, E.; Montes, J.; Silva, C. Medidores de deformación por resistencia: Galgas extensiométricas. Sci. Tech. Año XIII 2007, 34, 7-12.

41. Iskander, M. Underground Sensing. Monitoring and Hazard Detection for Environment and Infrastructure; Academic Press: Cambridge, MA, USA, 2018.

42. Figliola, R.S.; Beasley, D.E. Mediciones Mecánicas: Teoría y Diseño; Alfaomega Grupo Editor: Mexico City, Mexico, 2003.

43. Askarinejad, H.; Dhanasekar, M.; Cole, C. Assessing the effects of track input on the response of insulated rail joints using field experiments. Proc. Inst. Mech. Eng. Part F J. Rail Rapid Transit 2012, 227, 176-187. [CrossRef]

44. Palo, M.; Galar, D.; Nordmark, T.; Asplund, M.; Larsson, D. Condition monitoring at the wheel/rail interface for decision-making support. Proc. Inst. Mech. Eng. Part F J. Rail Rapid Transit 2014, 228, 705-715. [CrossRef]

45. Ahmad, S.S.; Mandal, N.K.; Chattopadhyay, G.; Powell, J. Development of a unified railway track stability management tool to enhance track safety. Proc. Inst. Mech. Eng. Part F J. Rail Rapid Transit 2013, 227, 493-516. [CrossRef]

46. Delprete, C.; Rosso, C. An easy instrument and methology for the monitoring and the diagnosis of a rail. Mech. Syst. Signal Process. 2008, 23, 940-956. [CrossRef]

47. Khairallah, D.; Blanc, J.; Cottineau, L.M.; Hornych, P.; Piau, J.-M.; Pouget, S.; Hosseingholian, M.; Ducreau, A.; Savin, F. Monitoring of railway structures of the high speed line BPL with bituminous and granular sublayers. Constr. Build. Mater. 2019, 211,337-348. [CrossRef]

48. Barriera, M.; Pouget, S.; Lebental, B.; Van Rompu, J. In Situ Pavement Monitoring: A Review. Infrastructures 2020, 5, 18. [CrossRef]

49. Zhang, S.; Koh, C.G.; Kuang, K.S.C. Proposed rail pad sensor for wheel-rail contact force monitoring. Smart Mater. Struct. 2018, 27, 115041. [CrossRef]

50. Ferdinand, P. The evolution of optical fiber sensors technologies during the35 last years and their applications in structure health monitoring. In Proceedings of the 7th European Workshop on Structural Health Monitoring, Nantes, France, 8-11 July 2014.

51. Rogers, A. Distributed optical-fibre sensing. Meas. Sci. Technol. 1999, 10, R75-R99. [CrossRef]

52. Cho, Y.T.; Alahbabi, M.N.; Brambilla, G.; Newson, T. Distributed Raman amplification combined with a remotely pumped EDFA utilized to enhance the performance of spontaneous Brillouin-based distributed temperature sensors. IEEE Photon Technol. Lett. 2005, 17, 1256-1258. [CrossRef]

53. Minardo, A.; Porcaro, G.; Giannetta, D.; Bernini, R.; Zeni, L. Real-time monitoring of railway traffic using slope-assisted Brillouin distributed sensors. Appl. Opt. 2013, 52, 3770-3776. [CrossRef]

54. Bao, X.; Chen, L. Recent Progress in Distributed Fiber Optic Sensors. Sensors 2012, 12, 8601-8639. [CrossRef] 
55. Speziale, S.; Marquardt, H.; Duffy, T. Brillouin Scattering and its Application in Geosciences. Rev. Mineral. Geochem. 2014, 78, 543-603. [CrossRef]

56. Hartog, A. An Introduction to Disbributed Optical Fibre Sensor; CRC Press: Boca Raton, FL, USA, 2017.

57. Hill, D. Distributed Acoustic Sensing (DAS): Theory and Applications. Front. Opt. 2015. [CrossRef]

58. Dou, S.; Lindsey, N.; Wagner, A.M.; Daley, T.M.; Freifeld, B.; Robertson, M.; Peterson, J.; Ulrich, C.; Martin, E.R.; Ajo-Franklin, J. Distributed Acoustic Sensing for Seismic Monitoring of The Near Surface: A Traffic-Noise Interferometry Case Study. Sci. Rep. 2017, 7, 1-12. [CrossRef]

59. Rodriguez, G.; Casas, J.; Villalba, S. SHM by DOFS in civil engineering: A review. Struct. Monit. Maint. 2015, 2, 357-382. [CrossRef]

60. Froggatt, M.; Moore, J. High-spatial-resolution distributed strainmeasurement in optical fiber with Rayleigh scatter. Appl. Opt. 1998, 37, 1735-1740. [CrossRef] [PubMed]

61. Lee, K.; Lee, K.; Ho, S. Exploration fo using FBG sensor for derailment detector. WSEAS Trasaction Syst. 2004, 3, 2433-2439.

62. Alemi, A.; Corman, F.; Lodewijks, G. Condition monitoring approaches for the detection of railway wheel defects. Proc. Inst. Mech. Eng. Part F J. Rail Rapid Transit 2016, 231, 961-981. [CrossRef]

63. Filograno, M.L.; Corredera, P.; Rodriguez-Plaza, M.; Andres-Alguacil, A.; Gonzalez-Herraez, M. Wheel Flat Detection in High-Speed Railway Systems Using Fiber Bragg Gratings. IEEE Sens. J. 2013, 13, 4808-4816. [CrossRef]

64. Wei, C.; Xin, Q.; Chung, W.H.; Liu, S.-Y.; Tam, H.-Y.; Ho, S.L. Real-Time Train Wheel Condition Monitoring by Fiber Bragg Grating Sensors. Int. J. Distrib. Sens. Netw. 2012, 8. [CrossRef]

65. Lai, C.; Kam, J.; Leung, D.; Lee, T.; Tam, A.; Ho, S.; Tam, H.; Liu, M. Development of a fiber-optic sensing system for train vibration and train weight measurements in Hon Kong. J. Sens. 2012, 2012, 365165. [CrossRef]

66. Alexakis, H.; Franza, A.; Acikgoz, S.; Dejong, M. A multi-sensing monitoring system to study deterioration of a railway bridge. In Proceedings of the 9th International Conference on Structural Health Monitoring of Intelligent Infrastructure (SHMII-9), St. Louis, MO, USA, 4-7 August 2019.

67. Buggy, S.J.; James, S.W.; Staines, S.; Carroll, R.; Kitson, P.; Farrington, D.; Drewett, L.; Jaiswal, J.; Tatam, R.P. Railway track component condition monitoring using optical fibre Bragg grating sensors. Meas. Sci. Technol. 2016, 27, 055201. [CrossRef]

68. Lai, C.C.; Au, H.Y.; Liu, M.S.Y.; Ho, S.L.; Tam, H.Y. Development of Level Sensors Based on Fiber Bragg Grating for Railway Track Differential Settlement Measurement. IEEE Sens. J. 2016, 16, 6346-6350. [CrossRef]

69. Yoon, H.-J.; Song, K.-Y.; Kim, J.-S.; Kim, D.-S. Longitudinal strain monitoring of rail using a distributed fiber sensor based on Brillouin optical correlation domain analysis. NDT E Int. 2011, 44, 637-644. [CrossRef]

70. Wheeler, L.; Take, W.; Hoult, N.; Le, H. The Use of Fiber Optic Sensing to Measure Distributed Rail Strains and Determine Rail Seat Forces Due to a Moving Train. Can. Geotech. J. 2019, 56, 1-13. [CrossRef]

71. Milne, D.; Le Pen, L.; Watson, G.; Thompson, D.; Powrie, W.; Hayward, M.; Morley, S. Proving MEMS Technologies for Smarter Railway Infraestructure. Procedia Eng. 2016, 143, 1077-1084. [CrossRef]

72. Crespo-Chacón, I.; García-De-La-Oliva, J.L.; Santiago-Recuerda, E. On the Use of Geophones in the Low-Frequency Regime to Study Rail Vibrations. Procedia Eng. 2016, 143, 782-794. [CrossRef]

73. Gao, R.; Zhang, L. Micromachined microsensors for manufacturing. IEEE Instrum. Meas. Mag. 2004, 7, 20-26. [CrossRef]

74. Albarbar, A.; Badri, A.; Sinha, J.K.; Starr, A. Performance evaluation of MEMS accelerometers. Measurement 2009, 42, 790-795. [CrossRef]

75. Coronado-Martínez, J. Análisis de las perturbaciones producidas por el sistema eléctrico de potencia de ferrocarriles de alta velocidad alimentados a frecuencia industrial. Vía Libre-Técnica 2014, 8, 81-100.

Publisher's Note: MDPI stays neutral with regard to jurisdictional claims in published maps and institutional affiliations. 